\title{
Microleakage at enamel and dentin margins with a bulk fills flowable resin
}

\author{
Nicola Scotti ${ }^{1}$, Allegra Comba ${ }^{1}$, Alberto Gambino ${ }^{1}$, Davide Salvatore Paolino ${ }^{2}$, \\ Mario Alovisi ${ }^{1}$, Damiano Pasqualini ${ }^{1}$, Elio Berutti ${ }^{1}$
}

Correspondence: Dr. Nicola Scotti

Email: nicola.scotti@unito.it

\begin{abstract}
'Department of Surgical Sciences, University of Turin Dental School, Via Nizza 230, 10126 Turin, Italy, ${ }^{2}$ Department of Mechanics, Politecnico di Torino, C.So Duca Degli Abruzzi 24, 10129 Turin, Italy
\end{abstract}

\begin{abstract}
Objective: The aim of this in vitro study was to evaluate the marginal sealing ability of a bulk fill flowable resin composite on both enamel and dentin substrates. Materials and Methods: 48 non-carious molars were selected and four Class-V cavities were prepared at the CEJ of each sample. Cavities were filled with Venus Diamond (Heraeus Kulzer); Venus Diamond Flow (Heraeus Kulzer) and Surefil SDR (Dentsply). Samples were divided into two groups: First group samples were immersed in a methylene blue solution for $30 \mathrm{~min}$ at $25^{\circ} \mathrm{C}$. Second group samples were artificially aged and then treated with methylene blue. Samples were sectioned in the center of the restoration and observed with a 40x stereomicroscope, and the percentage of cavity infiltration was calculated. Results: Results were analyzed statistically by ANOVA $(P<0.05)$. The amount of infiltration was significantly lower for the enamel substrate compared with dentin $(P=0.0001)$ and in samples immediately immersed in methylene blue compared with those that were artificially aged $(P=0.011)$. The interaction between the composite material and the marginal substrate significantly affected dye penetration $(P=0.006)$. Conclusions: Bulk fill flowable resins provided significantly better marginal seal in dentin, both before and after artificial ageing. Nanohybrid resin composites and bulk fill flowable resins showed similar microleakage values at enamel margins. Bulk fills flowable resins provided significantly better marginal seal in dentin, both before and after artificial ageing. Nanohybrid resin composites and bulk fill flowable resins showed similar microleakage values at enamel margins.
\end{abstract}

Key words: Artificial aging, bulk fill, dentin, enamel, microleakage

\section{INTRODUCTION}

Today, composite resins are considered materials of choice in restorative dentistry because of the increasing demand for high-quality esthetic results in everyday practice. Nevertheless, despite the continuous evolution of these resins, problems such as polymerization shrinkage and marginal microleakage still occur. ${ }^{[1]}$ Furthermore, with high-viscosity composite resin, it is difficult to obtain perfect adaptation to theinternal cavity surface and proper marginal seal of the cavity. ${ }^{[2]}$ Bulk Fill flowable resins with improved mechanical and chemical characteristics have recently been introduced. Flowable resins composites are low-viscosity materials with the reduced percentage of inorganic filler particles (44-55\% in volume) and higher amount of resinous components. Consequently, the polymerization process leads to an important volumetric contraction, but with minimal stress contraction. ${ }^{[3,4]}$

According to Hooke's Law, stress is determined by volumetric shrinkage and the elastic modulus of the material. ${ }^{[5]}$ Flowable composites, with their low elastic modulus, compete with stress development, potentially helping to maintain the marginal seal of the restoration. Moreover, flowable composites are readily workable and adaptable to cavity walls ${ }^{[6]}$ and their use can reduce marginal defects in restorations. ${ }^{[7,8]}$

\footnotetext{
How to cite this article: Scotti N, Comba A, Gambino A, Paolino DS, Alovisi M, Pasqualini D, Berutti E. Microleakage at enamel and dentin margins with a bulk fills flowable resin. Eur J Dent 2014;8:1-8. 
Today, the use of composites in extensive posterior cavities is still associated with some clinical challenges. Tight marginal seal is a fundamental goal for the clinician, because gap formation between the cavity and restorative material cannot prevent demineralization along with cavity margins. ${ }^{[9]}$ Above all, seal may be difficult to obtain in extensive composite restorations with cervical cavity margins that extend below the cemento-enamel junction, leaving no cervical enamel. Recent studies have shown increased marginal leakage when the cervical margin is located below the cemento-enamel junction. ${ }^{[2,10,11]}$ It is well-known that adhesion strength and the quality of marginal sealing have different predictability on enamel versus dentin. ${ }^{[10]}$ Adhesion has been demonstrated to be either micro-mechanical, due to the penetration of the bonding resin inside the microscopic and submicroscopic surface imperfections of the enamel and dentin and chemical, due to the partial dentin demineralization that leave a substantial amount of hydroxyapatite crystals around the collagen fibrils. The ability of the adhesive resin to infiltrate enamel and dentin is related to the surface wettability and it depends on the amount of surface free energy of dental substrate, which is directly proportional to the level of mineralization and indirectly proportional to the percentage of organic tissue. This clearly explains the higher predictability of adhesion to enamel compared with dentin. ${ }^{[12]}$

One possible solution to the weaker seal on dentin is the use of more adaptable flowable resins on enamel-free margins to interpose an elastic layer of $0.5-1 \mathrm{~mm}$ between the dental substrate and the restoration materials. ${ }^{[13,14]}$ Recently, new bulk fill flowable composites have been introduced. One of these, Surefil SDR (Dentsply, Milford, DE, USA), is mono-component light-curing composite material containing fluoride and having the ability to guarantee an intimate contact with cavity surfaces. ${ }^{[15]}$ It has minimal internal polymerization stresses because of longer pre-gel phase, which is accomplished by using "polymerization modulator" that interacts with camphoroquinone to reduce the contraction modulus and increase the number of linear bonds. The immediate result is lower shrinkage stress and preserved polymerization degree. ${ }^{[16]}$

To the best of our knowledge, there is no reported study assessing the degree of microleakage of these new flowable resins on both enamel and dentin. The aim of this in vitro study was to assess the marginal sealing quality of different composite resins on both enamel and dentin substrates, before and after artificial aging. The null hypothesis tested is that bulk-fill flowable composite resins do not lead to better marginal seal on enamel or dentin, in comparison with nanohybrid composite materials.

\section{MATERIALS AND METHODS}

\section{Sample preparation}

In total, 48 sound molars, with neither carious lesions nor restorations, which were recently extracted for periodontal reasons were selected for this in vitro study. Each tooth underwent scaling and root planing with an ultrasonic device to remove residual organic tissue. Then, the teeth were immersed in $2.6 \%$ sodium hypochlorite solution and rinsed with running water for $10 \mathrm{~min}$.

Using a cylindrical diamond bur under air-water cooling, an experienced operator prepared four square cavities $(h \times w \times l=2 \mathrm{~mm} \times 2 \mathrm{~mm} \times 2 \mathrm{~mm})$, one on each surface of the sample (mesial, distal, lingual, vestibular) at the cemento-enamel junction. The margins of the cavities were butt-joint finished with fine-grit diamond bur, half with enamel and half with dentin/cementum.

\section{Restorative procedures}

The adhesive system used for all samples was three-step etch-and-rinse system (Optibond FL, Kerr, Orange, CA, USA), applied following the manufacturer's instructions.

All prepared samples were randomly divided into three groups of 16 teeth each according to the restoration material used: Group 1, Venus Diamond (Heraeus Kulzer, Hanau, Germany); Group 2, Venus Diamond Flow (Heraeus Kulzer, Hanau, Germany); and Group 3: Surefil SDR flow (Dentsply, York, PA, USA) [Table 1]. All samples were restored using bulk technique and subsequently polymerized for $20 \mathrm{~s}$ with a LED lamp (Translux Power Blue, Heraeus Kultzer, Hanau; Germany) at $1000 \mathrm{~mW} / \mathrm{cm}^{2}$. After $24 \mathrm{~h}$, the restorations were finished with fine-grit diamond bur, mounted on red-ring handpiece, polished with a graded series of flexible discs (Sof-Lex, 3M ESPE, St. Paul, MN, USA) and stored in distilled water at $37^{\circ} \mathrm{C}$ for 7 days. The samples were completely sealed with two layers of nail polish, leaving 1-mm window around the four cavity margins.

\section{Aging procedures and microleakage analysis}

Each group was then divided into two subgroups $(n=8$ each) according to the artificial aging protocol. Samples in each subgroup were immediately immersed in a 1:10 solution of the tracer dye methylene blue for $30 \mathrm{~min}$ at $25^{\circ} \mathrm{C}$. The teeth were removed from the dye, brushed 


\begin{tabular}{|c|c|c|c|c|c|}
\hline Material & Material type & Matrix type & Filler type & Filler diameter & Filler loading \\
\hline $\begin{array}{l}\text { Surefil SDR flow: } \\
\text { Dentsply, USA }\end{array}$ & $\begin{array}{l}\text { Flowable, fluoride } \\
\text { ion release, up to } \\
4 \mathrm{~mm} \text { thickness, low } \\
\text { shrinkage stress }\end{array}$ & $\begin{array}{l}\text { Polymerization } \\
\text { modulator, dimethacrylate } \\
\text { resins }(<10 \% \mathrm{wt}) \\
\text { UDMA }(<25 \% \mathrm{wt})\end{array}$ & $\begin{array}{l}\text { Ba-B-F-Al silicate glass } \\
\text { ( }<50 \% \mathrm{wt}), \mathrm{SiO}_{2} \text {, amorphous } \\
\text { (<5\% wt), } \mathrm{Sr}-\mathrm{Al} \text { silicate glass } \\
\text { ( }<50 \% \mathrm{wt}), \mathrm{TiO}_{2}(<1 \% \mathrm{wt})\end{array}$ & Not specified & Not specified \\
\hline $\begin{array}{l}\text { Venus diamond } \\
\text { flow, Heraeus } \\
\text { Kulzer, Germany }\end{array}$ & $\begin{array}{l}\text { Flowable, } \\
\text { nano-hybrid, tixotropic, } \\
\text { multifunctional }\end{array}$ & UDMA, EBADMA & $\begin{array}{l}\text { Ba-B-F-Al silicate } \\
\text { glass, } \mathrm{YbF}_{3}, \mathrm{SiO}_{2}\end{array}$ & $20 \mathrm{~nm}-5 \mu \mathrm{m}$ & $\begin{array}{l}41 \% \text { vol } \\
65 \% \text { wt }\end{array}$ \\
\hline $\begin{array}{l}\text { Venus Diamond, } \\
\text { Heraeus Kulzer, } \\
\text { Germany }\end{array}$ & $\begin{array}{l}\text { Non flowable universal } \\
\text { "nanocomposite" } \\
\text { (microfill) }\end{array}$ & TCD-di-HEA, UDMA & $\begin{array}{l}\text { Ba-A-F glass, "Highly } \\
\text { discrete" }\end{array}$ & $5 \mathrm{~nm}-20 \mu \mathrm{m}$ & $\begin{array}{l}64 \% \text { vol } \\
80 \% \text { wt }\end{array}$ \\
\hline
\end{tabular}

under tap water for $1 \mathrm{~min}$ and embedded in transparent acrylic resin. The samples were sectioned longitudinally in the middle of the composite restoration, using a microtome under water cooling at low speed. Four sections were obtained for each tooth. The samples in each subgroup B were subjected to 1000 thermal cycles of $5 \pm 2{ }^{\circ} \mathrm{C}$ to $55 \pm 2{ }^{\circ} \mathrm{C}$ with dwell time of $60 \mathrm{~s}$ and then immersed in artificial saliva [Table 2] for 12 months, to artificially age the hybrid layer. After this, the subgroup $B$ teeth were immersed in methylene blue solution (1:10) for $30 \mathrm{~min}$ at $25^{\circ} \mathrm{C}$, brushed and sectioned as described for subgroup.

For all sections, pictures of the restoration interface were taken under $\times 40$ stereomicroscope (SMZ 140 N2GG, Motic, Wetzlar, Germany). The images were analyzed using image analysis software (Adobe Photoshop CS5, Microsoft, CA, USA) to assess the percentage of dye penetration relative to the total length of the restoration interface (100\%) [Figure 1].

\section{Statistical analysis}

Based on the statistical analysis to evaluate the effects of substrate (enamel/dentin margins), time (artificial aging) and material (Venus Diamond, Venus Diamond Flow, Surefil SDR) and their interactions on marginal infiltration, analysis of variance (ANOVA) was performed. Differences were considered statistically significant for $P<0.05$. Statistical analyses were performed using SW Minitab software (ver. 15, Minitab Inc., State College, PA, USA).

\section{RESULTS}

The mean values for dye penetration at the enamel and dentin margins, expressed as a percentage of dye penetration through the composite-tooth interface $( \pm S D)$, are presented in Table 3 . Based on the ANOVA results [Table 4, Figures 2 and 3], both substrate $(P=0.0001)$ and artificial aging $(P=0.011)$,

\begin{tabular}{lc} 
Table 2: Compounds and concentration of artificial \\
saliva solution \\
\hline Compound & Concentration (g/l) \\
$\mathrm{NaPO}_{4}$ & 0.780 \\
$\mathrm{NaCl}$ & 0.5 \\
$\mathrm{KCl}$ & 0.5 \\
$\mathrm{CaCl}$ & 0.795 \\
$\mathrm{NaS}$ & 0.05 \\
$\left(\mathrm{NH}_{4}\right)_{2} \mathrm{SO}_{4}$ & 0.3 \\
$\mathrm{Citric} \mathrm{acid}$ & 0.05 \\
$\mathrm{NaCO}$ & 0.1 \\
Urea & 1.0 \\
\hline
\end{tabular}

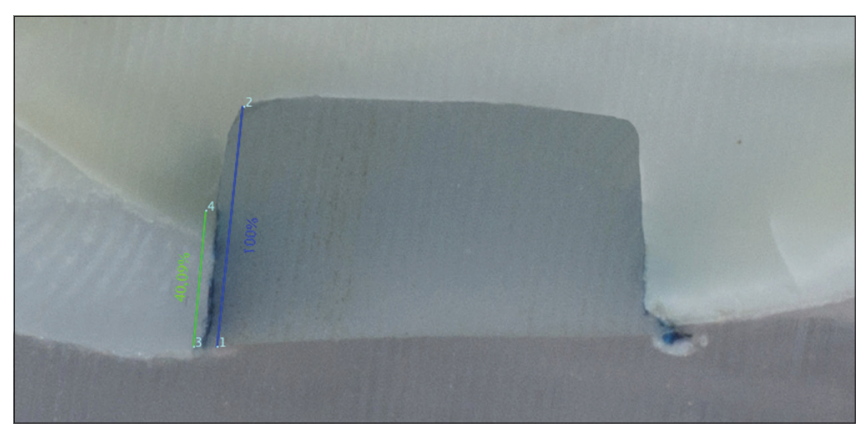

Figure 1: $\times 40$ picture of a sectioned sample with the calculation of the percentage of dye penetration relative to the total length of the restoration interface $(100 \%)$

but not material $(P=0.204)$, had a significant effect on the amount of microleakage. Moreover, the interaction between the composite material and the substrate was statistically significant $(P=0.006)$. First-order interaction plot [Figure 3] confirmed the ANOVA results and showed that only the interaction between the composite material and the margin substrate significantly affected the percentage of dye penetration along the composite-tooth interface.

\section{DISCUSSION}

In the current study, we examined the microleakage of different types of composite resins at enamel and 


\begin{tabular}{|c|c|c|c|c|}
\hline \multirow[t]{2}{*}{ Groups } & \multicolumn{2}{|c|}{ Without aging (subgroup A) } & \multicolumn{2}{|c|}{ With aging (subgroup B) } \\
\hline & Enamel & Dentine & Enamel & Dentine \\
\hline 1 (venus diamond) & $19.01(\mathrm{SD} \pm 9.35)$ & $45.69(\mathrm{SD} \pm 26.50)$ & $23.07(\mathrm{SD} \pm 9.08)$ & $53.10(\mathrm{SD} \pm 26.52)$ \\
\hline 2 (venus diamond flow) & $21.60(\mathrm{SD} \pm 7.63)$ & $32.32(\mathrm{SD} \pm 22.51)$ & $25.35(\mathrm{SD} \pm 11.55)$ & $40.04(\mathrm{SD} \pm 23.31)$ \\
\hline $3(\mathrm{SDR})$ & $21.18(\mathrm{SD} \pm 6.97)$ & $30.45(\mathrm{SD} \pm 18.90)$ & $25.33(\mathrm{SD} \pm 13.68)$ & $37.18(\mathrm{SD} \pm 27.66)$ \\
\hline
\end{tabular}

SD: Standard deviation, SDR: Smart dentine replacement
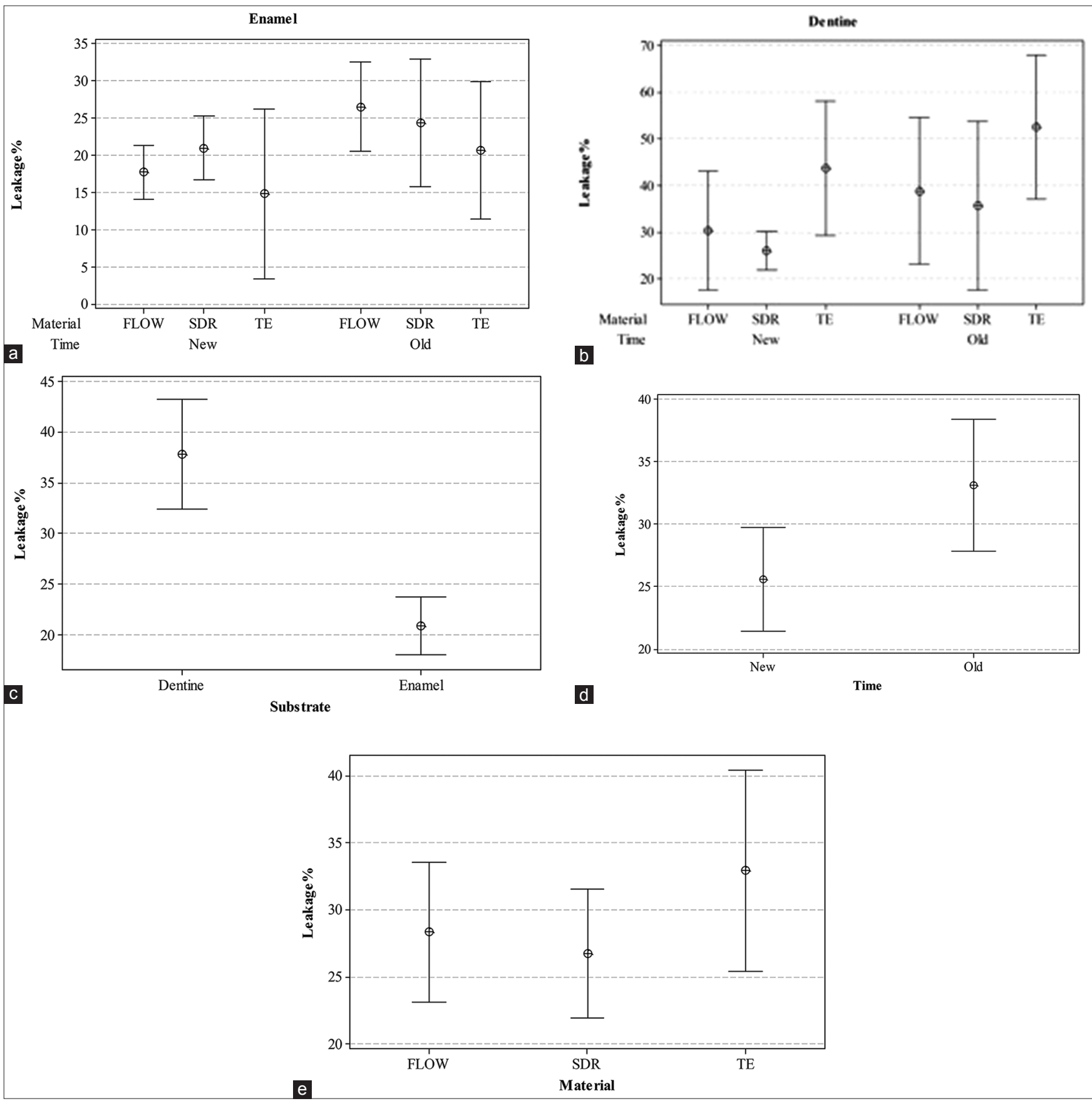

Figure 2: 95\% interval plots for the mean value of microleakage. (a) Confidence intervals within enamel group; (b) Confidence intervals within dentin group; (c) Confidence intervals for substrate factor; (d) Confidence intervals for time factor; (e) Confidence intervals for material factor. If the mean value corresponding to a level of the factor is not included in the confidence intervals corresponding to any other level of the factor, then the factor is statistically significant with a significance level equal to $5 \%$ 


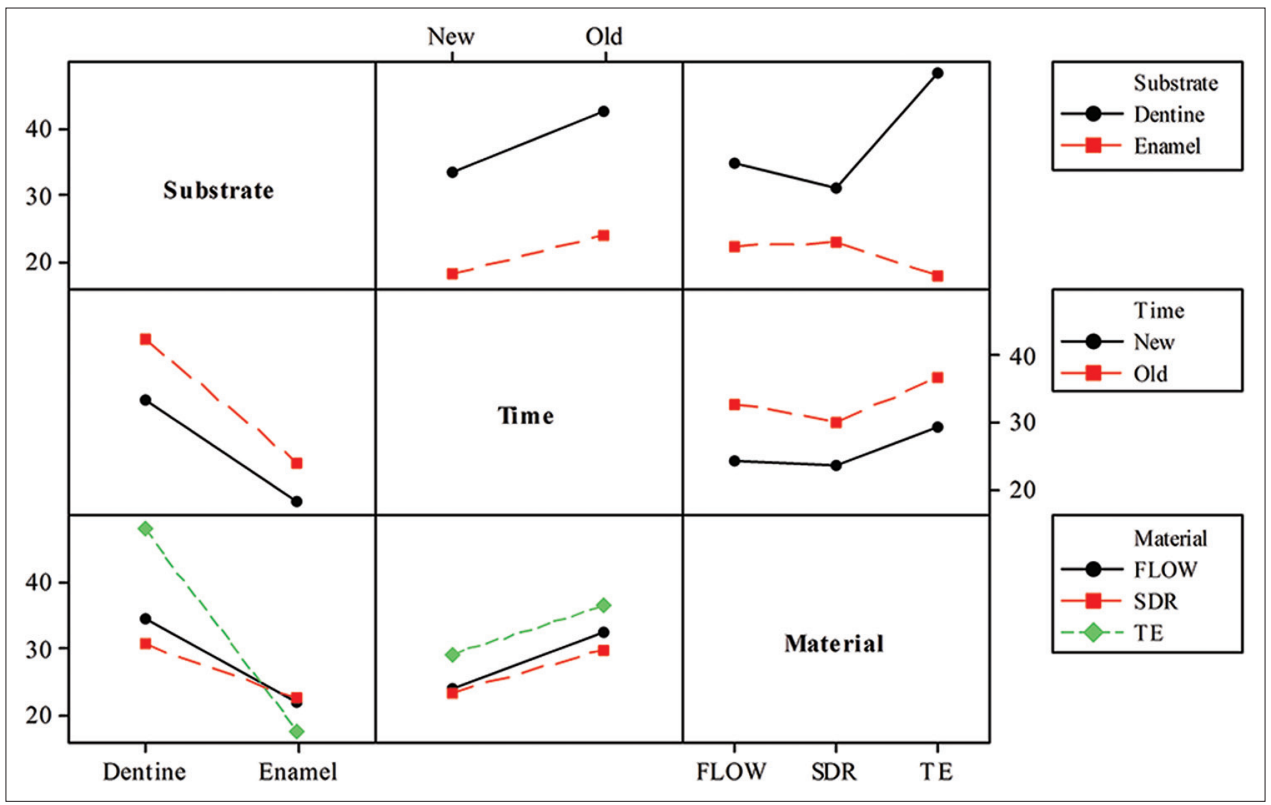

Figure 3: First order interaction plot showing the interactions between substrate, time and materials. Large non-parallelism among lines in substrate-material interaction plot points out statistical significance of the corresponding interaction

\begin{tabular}{|c|c|c|c|c|c|}
\hline Source & DF & SS & MS & $F$ & $P$ \\
\hline Substrate & 1 & 8611.8 & 8611.8 & 33.81 & 0.0001 \\
\hline Time & 1 & 1703.7 & 1703.7 & 6.69 & 0.011 \\
\hline Material & 2 & 821.3 & 410.7 & 1.61 & 0.204 \\
\hline Substrate*time & 1 & 69.5 & 69.5 & 0.27 & 0.602 \\
\hline Substrate*material & 2 & 2769.2 & 1384.6 & 5.44 & 0.006 \\
\hline Time*material & 2 & 23.4 & 11.7 & 0.05 & 0.955 \\
\hline Substrate*time* material & 2 & 52.2 & 26.1 & 0.10 & 0.903 \\
\hline Error & 108 & 27506.1 & 254.7 & & \\
\hline
\end{tabular}

ANOVA: Analysis of variance, DF: Degree of freedom,

SS: Sum of squares, MS: Mean squares

dentin margins, both before and after artificial aging. The data lead to the conclusion that the initial null hypothesis must be partially rejected because flowable composites, in particular, bulk-fill flowable composite resins, showed less marginal microleakage on dentin compared with nanohybrid high-viscosity composite resins. The latter, however, maintained the best sealing ability, both before and after artificial aging, when applied on enamel margins.

One of the most important aims of cavity restorations is to establish predictable marginal seal in order to prevent microleakage and its clinical consequences such as marginal discrepancies, marginal staining, recurrent caries, sensitivity and pain. ${ }^{[16,17]}$ Microleakage, an important property used to assess the success of restorative material, is described as the chemically undetectable passage of bacteria, fluids, molecules or ions between the cavity walls and the restorative materials. ${ }^{[17]}$ Dye penetration is an established in vitro method for investigating marginal leakage along tooth-restoration interfaces and is generally assessed after cutting the teeth in the longitudinal direction. ${ }^{[18-20]}$ Various tracer dyes are available for microleakage studies and there appears to be no significant difference in tracer penetration among fuchsin, silver nitrate and methylene blue. ${ }^{[21]}$ Methylene blue is one of the most common tracers and can be used at different concentrations. ${ }^{[22,23]}$ Some authors have suggested that because of the small surface area of the particles (approximately 0.52 $\mathrm{nm}^{2}$ ), methylene blue may lead to an overestimation of leakage at tooth-restoration interfaces. ${ }^{[24]}$ However, study by Ernst $e t$ al. underlined a correlation between SEM analysis and 30-min immersion in methylene blue, especially for enamel margins. For this reason, immersion in $2 \%$ methylene blue for $30 \mathrm{~min}$ at $25^{\circ} \mathrm{C}$ was used in the present study and this immersion time was suitable for marking marginal gaps. ${ }^{[18]}$

Marginal infiltration is most commonly assessed by numerically scoring the tooth-restoration interface on a scale of 0 and 3 , according to the parameters previously showed in literature. ${ }^{[24]}$ However, this method is influenced by the scorer's ability to evaluate substrate infiltration and poor inter-examiner reliability has been reported, highlighting the subjective nature of evaluating microleakage by numerically scoring dye penetration. ${ }^{[25]}$ To address this issue in the present 
in vitro study, the percentage of marginal leakage was calculated with the help of image analysis software. The total surface of the restoration at the composite-cavity interface was set as $100 \%$ and the software calculated the amount of tissue infiltrated as a percentage of the total length.

The percentage of infiltration was calculated at the tooth-restoration interface for both the enamel and dentin, which were filled with three different materials: nanohybrid high-viscosity composite resin (Venus Diamond), flowable resin (Venus Diamond Flow) and new bulk-fill flowable resin (Surefil SDR). Because of the study setup, flowable resins were placed in the cavities without covering it with resin composite. In fact, in order to evaluate the efficacy of the tested materials to avoid the marginal microleakage on both enamel and dentin, it was necessary to seal the interfaces exclusively with the material object of study. Three-step etch-and-rinse adhesive system (Optibond FL) was used because it has been demonstrated that surface treatment with an etch-and-rinse system provides better marginal sealing than self-etch adhesive system. ${ }^{[26]}$ This may be explained by the surface morphological pattern created after phosphoric acid application. ${ }^{[27]}$ Moreover, Optibond FL is considered more durable and better able to produce resin-dentin bonds compared with one or two-step adhesive. ${ }^{[28]}$

None of the interfaces showed an absence of infiltration, although the degree of infiltration differed in relation to the substrate, the aging process and the material. The dye penetration was significantly affected by the marginal substrate and its interaction with the resin material $(P=0.006)$. The percentage of infiltration on enamel was significantly lower than that on dentin $(P=0.0001)$. This finding is consistent with previous reports regarding adhesion on enamel and dentin. The presence of less dye penetration and better marginal seal on enamel is related to the low organic content of enamel compared with dentin; dentin has a complex structure rich in organic molecules, making adhesion to dentin more variable and difficult to achieve. ${ }^{[6]}$

On enamel margins, nanohybrid composites such as the one tested in this study showed low percentage of infiltration, confirming that the quality of adhesion on enamel is able to overcome curing shrinkage, regardless of the volumetric shrinkage of the resinous material employed. In contrast, at dentinal margins, flowable resins lead to significantly better results regarding microleakage, with Surefil SDR providing the best results. This can be explained by their lower stress due to low elastic modulus, compared with the higher elastic modulus of conventional composites, ${ }^{[29]}$ and their lower wettability. ${ }^{[30]}$ Furthermore, flowable composites can be readily inserted into small cavities and are expected to adapt better to the internal cavity wall than conventional restorative composites, which are more viscous. ${ }^{[31]}$ These features of flowable composites can account for our findings of their superior behavior on dentin substrate, where adhesive processes are less predictable and more difficult achieve. ${ }^{[32]}$ Our results are in agreement with several previous studies showing significant effects of flowable composites as gingival increments in reducing the microleakage of composite restorations. ${ }^{[2]}$

Another important aim of this in vitro study was to evaluate changes in marginal infiltration following artificial aging, which was performed through thermocycling and immersion in artificial saliva for 12 months. Dental restorations are subjected to constant and extreme changes in the oral environment, with large fluctuations in temperature and $\mathrm{pH} .{ }^{[33,34]}$ Restorative materials are constantly exposed to thermal variations during the intake of food and fluids at various temperatures. ${ }^{[35]}$ Thus, thermocycling is an important procedure for testing the sealing ability of restorative material. ${ }^{[36]}$ Thermally induced stresses, which may lead to gap formation and microleakage, result from the mismatch between the coefficients of thermal expansion for the restorative material and the natural tooth structure. ${ }^{[37]}$ Previous studies have demonstrated that thermocycling is the most influential factor in enhancing the process of microleakage. ${ }^{[36]} \mathrm{A}$ previous paper revealed effects of the wide range of cycle numbers, temperatures and exposure times for in vitro thermocycling regimens. ${ }^{[38]}$ The conditions used in the present study $\left(1000\right.$ cycles of $5 \pm 2^{\circ} \mathrm{C}$ to $55 \pm 2^{\circ} \mathrm{C}$ with 60 -s dwell time) were based on the conditions used in recent studies on Class $\mathrm{V}$ restorations. ${ }^{[39,40]}$

To simulate the oral environment and further increase the aging effect, the teeth were stored in artificial saliva for 12 months, which induced water sorption and the elution of suboptimally polymerized monomers. ${ }^{[41]}$ The artificially aged teeth showed a significant increase in dye penetration on both enamel and dentin margins, with more favorable sealing performance at the enamel-restoration interface. The higher penetration of methylene blue dye into 
the samples stored for 12 months in saliva may be attributable to the physiological degradation of the restorative resins caused by contact with oral cavity fluids. Moreover, greater dye penetration on dentin may be associated with the presence of matrix metalloproteinases in demineralized dentin; once activated by acid-etching, the metalloproteinases can slowly degrade collagen fibrils of the resin-infiltrated hybrid layer. ${ }^{[28]}$

Despite an effect of aging $(P=0.011)$, the substrate and composite material used were the main determining factors of microleakage in the present study. The nanohybrid composites performed better on enamel margins, while the flowable resins, particularly the low-shrinkage flowable resin, performed better on dentin margins in both subgroup A, which was not treated with the artificial aging process and subgroup A, which was artificially aged. Thus, the type of substrate and the material employed are the key parameters to be considered when restoring a tooth.

Within the limits of this in vitro study, we can assert that both before and after artificial aging treatment, the microleakage in enamel was not influenced by the filling material tested in this study. On dentin Surefil SDR and Venus Diamond Flow provide better marginal seal than Venus Diamond.

\section{REFERENCES}

1. Ferracane JL. Resin composite - State of the art. Dent Mater 2011;27:29-38.

2. Sadeghi M, Lynch CD. The effect of flowable materials on the microleakage of Class II composite restorations that extend apical to the cemento-enamel junction. Oper Dent 2009;34:306-11.

3. Labella R, Lambrechts P, Van Meerbeek B, Vanherle G. Polymerization shrinkage and elasticity of flowable composites and filled adhesives. Dent Mater 1999;15:128-37.

4. Stavridakis MM, Dietschi D, Krejci I. Polymerization shrinkage of flowable resin-based restorative materials. Oper Dent 2005;30:118-28.

5. Watts DC, Marouf AS, Al-Hindi AM. Photo-polymerization shrinkage-stress kinetics in resin-composites: Methods development. Dent Mater 2003;19:1-11.

6. Cadenaro M, Breschi L, Rueggeberg FA, Suchko M, Grodin E, Agee K, et al. Effects of residual ethanol on the rate and degree of conversion of five experimental resins. Dent Mater 2009;25:621-8.

7. Hilton TJ. Can modern restorative procedures and materials reliably seal cavities? In vitro investigations. Part 1. Am J Dent 2002;15:198-210.

8. Kwon OH, Kim DH, Park SH. The influence of elastic modulus of base material on the marginal adaptation of direct composite restoration. Oper Dent 2010;35:441-7.

9. Krämer N, García-Godoy F, Frankenberger R. Evaluation of resin composite materials. Part II: in vivo investigations. Am J Dent 2005;18:75-81.

10. Wibowo G, Stockton L. Microleakage of Class II composite restorations. Am J Dent 2001;14:177-85.

11. Ozel E, Korkmaz Y, Attar N. Influence of location of the gingival margin on the microleakage and internal voids of nanocomposites. J Contemp Dent Pract 2008;9:65-72.
12. Cardoso MV, de Almeida Neves A, Mine A, Coutinho E, Van Landuyt K, De Munck J, et al. Current aspects on bonding effectiveness and stability in adhesive dentistry. Aust Dent J 2011;56 Suppl 1:31-44

13. Loguercio AD, Moura SK, Pellizzaro A, Dal-Bianco K, Patzlaff RT, Grande RH, et al. Durability of enamel bonding using two-step self-etch systems on ground and unground enamel. Oper Dent 2008;33:79-88.

14. Pashley DH. Smear layer: Physiological considerations. Oper Dent Suppl 1984;3:13-29.

15. Van Landuyt KL, Mine A, De Munck J, Jaecques S, Peumans M, Lambrechts $\mathrm{P}$, et al. Are one-step adhesives easier to use and better performing? Multifactorial assessment of contemporary one-step self-etching adhesives. J Adhes Dent 2009;11:175-90.

16. Ilie N, Hickel R. Investigations on a methacrylate-based flowable composite based on the SDR ${ }^{\mathrm{TM}}$ technology. Dent Mater 2011;27:348-55.

17. Kidd EA. Microleakage: a review. J Dent 1976;4:199-206.

18. Ernst CP, Galler P, Willershausen B, Haller B. Marginal integrity of class V restorations: SEM versus dye penetration. Dent Mater 2008;24:319-27.

19. Ghasemi A, Torabzadeh H, Mahdian M, Afkar M, Fazeli A, Akbarzadeh Baghban A. Effect of bonding application time on the microleakage of Class V sandwich restorations. Aust Dent J 2012;57:334-8.

20. Kusgoz A, Ülker M, Yesilyurt C, Yoldas OH, Ozil M, Tanriver M. Silorane-based composite: Depth of cure, surface hardness, degree of conversion, and cervical microleakage in Class II cavities. J Esthet Restor Dent 2011;23:324-35.

21. Heintze S, Forjanic M, Cavalleri A. Microleakage of Class II restorations with different tracers - Comparison with SEM quantitative analysis. J Adhes Dent 2008;10:259-67.

22. Fabianelli A, Sgarra A, Goracci C, Cantoro A, Pollington S, Ferrari M. Microleakage in Class II restorations: Open vs closed centripetal build-up technique. Oper Dent 2010;35:308-13.

23. Bedran de Castro AK, Pimenta LA, Amaral CM, Ambrosano GM. Evaluation of microleakage in cervical margins of various posterior restorative systems. J Esthet Restor Dent 2002;14:107-14.

24. Abd El Halim S, Zaki D. Comparative evaluation of microleakage among three different glass ionomer types. Oper Dent 2011;36:36-42.

25. Umer F, Naz F, Khan FR. An in vitro evaluation of microleakage in class $\mathrm{V}$ preparations restored with hybrid versus silorane composites. J Conserv Dent 2011;14:103-7.

26. De Munck J, Shirai K, Yoshida Y, Inoue S, Van Landuyt K, Lambrechts $\mathrm{P}$, et al. Effect of water storage on the bonding effectiveness of 6 adhesives to Class I cavity dentin. Oper Dent 2006;31:456-65.

27. Atoui JA, Chinelatti MA, Palma-Dibb RG, Corona SA. Microleakage in conservative cavities varying the preparation method and surface treatment. J Appl Oral Sci 2010;18:421-5.

28. Pashley DH, Tay FR, Breschi L, Tjäderhane L, Carvalho RM, Carrilho M, et al. State of the art etch-and-rinse adhesives. Dent Mater 2011;27:1-16

29. Cadenaro M, Marchesi G, Antoniolli F, Davidson C, De Stefano Dorigo E, Breschi L. Flowability of composites is no guarantee for contraction stress reduction. Dent Mater 2009;25:649-54.

30. Sadeghi M. Influence of flowable materials on microleakage of nanofilled and hybrid Class II composite restorations with LED and QTH LCUs. Indian J Dent Res 2009;20:159-63.

31. Ikeda I, Otsuki M, Sadr A, Nomura T, Kishikawa R, Tagami J. Effect of filler content of flowable composites on resin-cavity interface. Dent Mater J 2009;28:679-85.

32. Carvalho RM, Manso AP, Geraldeli S, Tay FR, Pashley DH. Durability of bonds and clinical success of adhesive restorations. Dent Mater 2012;28:72-86.

33. Geis-Gerstorfer J. In vitro corrosion measurements of dental alloys. J Dent 1994;22:247-51.

34. Kidd E. Essentials of Dental Caries: The Disease and its Management. $3^{\text {rd }}$ ed. Oxford UK: OUP Oxford; 2005.

35. Sharma RD, Sharma J, Rani A. Comparative evaluation of marginal adaptation between nanocomposites and microhybrid composites exposed to two light cure units. Indian J Dent Res 2011;22:495.

36. Wahab FK, Shaini FJ, Morgano SM. The effect of thermocycling on microleakage of several commercially available composite Class V restorations in vitro. J Prosthet Dent 2003;90:168-74. 
37. Versluis A, Douglas WH, Sakaguchi RL. Thermal expansion coefficient of dental composites measured with strain gauges. Dent Mater 1996;12:290-4.

38. Nalcaci A, Ulusoy N. Effect of thermocycling on microleakage of resin composites polymerized with LED curing techniques. Quintessence Int 2007;38:e433-9.

39. Brackett WW, Haisch LD, Pearce MG, Brackett MG. Microleakage of Class $\mathrm{V}$ resin composite restorations placed with self-etching adhesives. J Prosthet Dent 2004;91:42-5.

40. Manhart J, Chen HY, Mehl A, Weber K, Hickel R. Marginal quality and microleakage of adhesive class V restorations. J Dent 2001;29:123-30.

41. Saboia VP, Silva FC, Nato F, Mazzoni A, Cadenaro M, Mazzotti G, et al. Analysis of differential artificial ageing of the adhesive interface produced by a two-step etch-and-rinse adhesive. Eur J Oral Sci 2009;117:618-24.

\begin{tabular}{|l|l|}
\hline \multicolumn{2}{|c|}{ Access this article online } \\
\hline Quick Response Code: & Website: \\
\hline & www.eurjdent.com \\
\cline { 2 - 2 } & \\
\hline
\end{tabular}

